\title{
A new metabolomic assay to examine inflammation and redox pathways following LPS challenge
}

\author{
Jung H Suh ${ }^{*}$, Robert Y Kim and Daniel S Lee
}

\begin{abstract}
Background: Shifts in intracellular arginine (Arg) and sulfur amino acid (SAA) redox metabolism modulate macrophage activation, polarization and phenotype. Despite their importance in inflammation and redox regulatory pathways, comprehensive analysis of these metabolic networks was not previously possible with existing analytical methods.
\end{abstract}

Methods: The Arg/thiol redox LC-MS/MS metabolomics assay permits simultaneous assessment of amino acids and derivative products generated from Arg and SAA metabolism. Using this assay, LPS-induced changes in macrophage amino acid metabolism were monitored to identify pathway shifts during activation and their linkage to cellular redox regulation.

Results: Metabolite concentrations most significantly changed after treatment of a macrophage-like cell line (RAW) with LPS for 24 hrs were citrulline (Cit) (48-fold increase), ornithine (Orn) (8.5-fold increase), arginine (Arg) (66\% decrease), and aspartic acid (Asp) (73\% decrease). The ratio Cit + Orn/Arg + Asp (CO/AA) was more sensitive to LPS stimulation than other amino acid ratios commonly used to measure LPS-dependent inflammation (e.g., SAM/SAH, GSH/GSSG) and total media NOx. The CO/AA ratio was also the first ratio to change significantly after LPS treatment (4 hrs). Changes in the overall metabolomic profile over time indicated that metabolic pathways shifted from Arg catabolism to thiol oxidation.

Conclusions: Simultaneous quantification of Arg and SAA metabolic pathway shifts following LPS challenge of macrophage indicate that, in this system, the Arg-Citrulline/NO cycle and arginase pathways are the amino acid metabolic pathways most sensitive to LPS-challenge. The cellular (Cit + Orn)/(Arg + Asp) ratio, which summarizes this pathway, was more responsive to lower concentrations of LPS and responded earlier than other metabolic biomarkers of macrophage activation including GSH redox. It is suggested that the CO/AA ratio is a redoxindependent early biomarker of macrophage activation. The ability to measure both the CO/AA and GSH-redox ratios simultaneously permits quantification of the relative effects of LPS challenge on macrophage inflammation and oxidative stress pathways. The use of this assay in humans is discussed, as are clinical implications.

Keywords: Macrophage, Lipopolysaccharide, Sub-clinical inflammation, Arginine metabolism, Redox regulation, Biomarker

\footnotetext{
* Correspondence: jsuh@chori.org

Nutrition and Metabolism Center, Children's Hospital Oakland Research Institute, Oakland, CA, USA
} 


\section{Background}

While a direct causal link between inflammation/oxidative stress and disease has not been proven, heightened systemic oxidative and inflammatory stress is strongly associated with the transition from health to disease [1-3]. For example, prospective epidemiological studies indicate that increases in oxidative stress and inflammation are associated with elevated risk of cognitive decline, cardiovascular disease, and cancer [4-8].

Non-proteinogenic metabolism of amino acids is a central part of the inflammation and redox environment. Arginine (Arg) and sulfur amino acid (SAA) metabolism play critical roles in regulating the physiological response to injury and oxidative stress [9-12]. These pathways are illustrated in Figure 1 and briefly described below.

Arginine (Arg) is a conditionally essential amino acid whose nutritional requirement is increased during inflammation [9-11]. During inflammation, Arg is catabolized primarily to citrulline (Cit) (Figure 1: rectangle) and ornithine (Orn) (Figure 1: rectangle) to generate NO, urea and the polyamines putrescine (Put), spermidine (Spd), and spermine (Spm) (Figure 1: hexagons) [9-11]. The products of Arg catabolism directly modulate inflammation by controlling endothelial function, leukocyte recruitment and activation, innate immunity, and extracellular matrix remodeling [9-11].

Metabolism of sulfur amino acids (SAA) occurs through four interconnected metabolic pathways - transmethylation, transsulfuration, GSH synthesis, and the $\gamma$ glutamyl-cycle (Figure 1: ovals) [13,14]. As shown, each of these cycles produce one sulfhydryl $(-\mathrm{SH})$ containing compound. These are, respectively, homocysteine (Hcy), cysteine (Cys), glutathione (GSH) and cysteinylglycine (Cysgly) (Figure 1: grey ovals). The homeostatic balance of these compounds is important for cellular redox regulation $[15,16]$. Excess accumulation of Hcy and Cys is pro-inflammatory in cells [17-20] and is also associated with increased cardiovascular disease risk [12,21-23]. GSH is the principal thiol antioxidant, and a key regulator of cellular protein thiol redox states $[15,16]$. In addition to its direct antioxidant function, the synthesis of GSH from its rate-limiting substrate Cys minimizes the toxicity of excess Cys accumulation and acts as a cellular Cys reserve [15,16]. In fact, the release of Cys on GSH breakdown is an important means of inter-organ Cys trafficking [24]. GSH is only catabolized by $\gamma$-glutamyl transpeptidase (GGT), which generates Cysgly dipeptide [24]. Microsomal dipeptidase enzymes hydrolyze Cysgly to yield Cys. Because Cysgly does not accumulate in cells, it does not contribute significantly to cellular redox regulation directly. GGT expression is increased in conditions of inflammation and oxidative stress and acts as an important part in the cellular redox regulation [25-27].
The Arg and SAA metabolic pathways are also impacted by metabolism of amino acids that are not directly a part of those pathways. For example, on Arg deficiency, amino acids such as aspartate, glutamate and proline (Figure 1: circles) can be utilized to regenerate Arg [28,29]. Cystathionine (Cysth), a precursor of Cys, is synthesized from homocysteine and serine $[13,14]$. Gly and Glu are also required for GSH formation. Thus, a comprehensive analysis of amino acids, in addition to directly focusing on metabolites in the Arg and SAA pathways, may be useful in identifying factors that contribute to Arg and SAA pathway shifts on inflammation and oxidative stress.

While several sensitive analytical techniques are available that quantify GSH redox states and secondary Arg metabolic intermediates [30-35], the method utilized here is the first that permits simultaneous monitoring of all amino acids and the major secondary metabolites in both Arg and SAA metabolism.

Our Arg/thiol redox metabolomics assay combines an isopropylchloroformate derivatization method previously developed for analyzing 20 major amino acids [36] with modifications that enable detection of reduced and oxidized thiols with minimal ex-vivo oxidation [37]. The assay targets the major amino acids and secondary metabolic products of Arg and SAA shown in Figure 1, a total of 34 metabolites. This report presents results of experiments using RAW murine macrophage-like cells to test the sensitivity of this assay in detecting metabolic shifts in both oxidative stress and inflammation pathways occurring following a challenge with bacterial LPS.

\section{Methods}

\section{Reagents}

Arginine (Arg), Citrulline (Cit), Putrescine (Put), Spermidine (Spd), Spermine (Spm), methionine (Met), methionine sulfoxide (MetSO), S-adenosylmethionine (SAM), S-adenosylhomocysteine (SAH), homocysteine (Hcy), homocystine (Hcy2), cystathionine (Cysth), cysteine (Cys), cystine (Cys2), glutathione (GSH), glutathione-disulfide (GSSG), cysteinyl-glycine (Cysgly), cysteinyl-glycine disulfide (Cysgly2), glycine (Gly), glutamine (Gln), and glutamate (Glu), of highest analytical grade were purchased from Sigma (St. Louis, MO). Homoglutathione was purchased from BACHEM. Stable isotopes, methioninemethyl- $\mathrm{D}_{3}$, Homocystine $\left(3,3,3,3,3^{\prime}, 4,4,4,4^{\prime}-\mathrm{D}_{8}\right)$, Cystine $\left(3,3,3^{\prime} 3^{\prime}-\mathrm{D}_{4}\right)$, and Glycine $\left({ }^{13} \mathrm{C}_{2},{ }^{15} \mathrm{~N}\right)$ were purchased from Cambridge Isotopes. S-Adenosylmethionine (methyl- $\mathrm{D}_{3}$ ) was obtained from CDN Isotopes (Quebec, Canada). All HPLC solvents were of the analytical grade available from Fisher Scientific. The EZ-FAAST kit used for sample and standard derivatization was purchased from Phenomenex (Torrance, CA). 


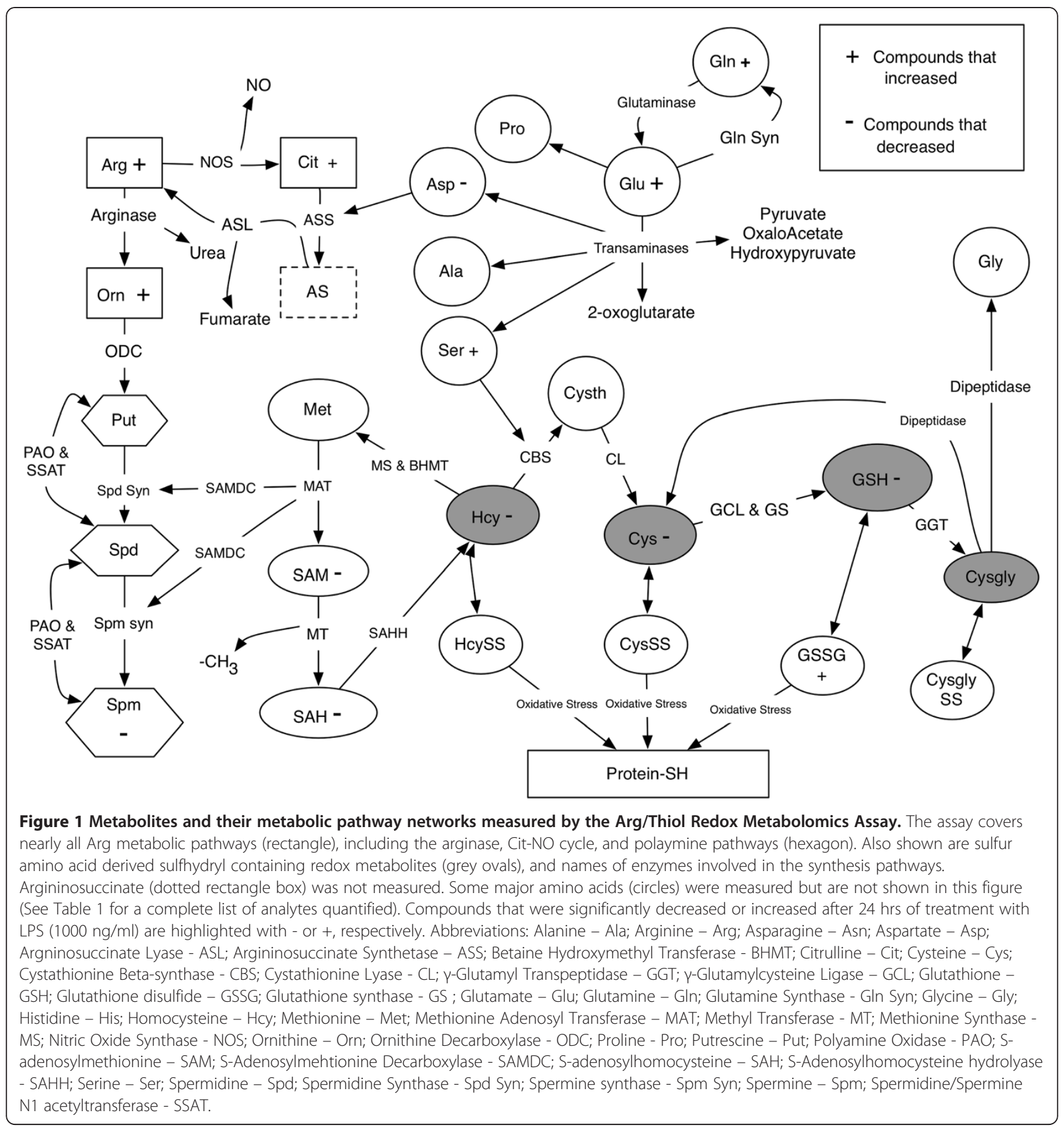

\section{Cell culture conditions}

RAW267.4 mouse macrophage cells (RAW) in phenolfree Dulbecco's minimal essential media (DMEM; Sigma) containing $5 \%$ heat-inactivated fetal bovine serum (FBS) were plated overnight in 6 well plates $\left(2 \times 10^{6}\right.$ cells/well $)$. To profile the concentration-dependent effects of LPS on amino acid metabolism, plated cells were incubated in media treated with or without $0.1,1,10,100$, and $1000 \mathrm{ng} / \mathrm{ml}$ bacterial lipopolysaccharide (LPS; type 055: B5) at $37^{\circ} \mathrm{C}$ for $24 \mathrm{hrs}$. For the time course experiments, cells were challenged with $10 \mathrm{ng} / \mathrm{ml} \mathrm{LPS}$ at $37^{\circ} \mathrm{C}$ for 2,4 , or 6 hrs. To quantify amino acid metabolites, cells were detached from the plate with Trypsin and washed twice with pre-warmed phosphate buffered saline. Cell pellets were resuspended in $200 \mu \mathrm{l}$ PBS buffer; cell number and viability were checked by tryphan blue exclusion assay. To quantify redox states of thiol amino acid metabolites, cell pellet suspensions were mixed with an equal volume of $20 \mathrm{mM}$ iodoacetamide (IAM) dissolved in $0.1 \mathrm{M}$ Tris$\mathrm{Cl}$ buffer ( $\mathrm{pH}$ 8.0) for $1 \mathrm{hr}$. Following IAM treatment, 
samples were deproteinized by mixing with an equal volume of $10 \%$ perchloric acid containing $0.2 \mathrm{mM}$ DTPA and centrifuged at $13000 \mathrm{rpm}$ for $5 \mathrm{~min}$. Acidified supernatants were collected and stored at $-80^{\circ} \mathrm{C}$ until analysis.

\section{Derivatization procedures}

Stock solutions $(10 \mathrm{mM})$ of amino acid standards were prepared in $5 \%$ perchloric acid containing $0.5 \mathrm{mM}$ DTPA. An internal standards mix contained $10 \mu \mathrm{M}$ solution of arginine $\left({ }^{15} \mathrm{~N}_{2}\right)$, glycine $\left({ }^{13} \mathrm{C}_{2},{ }^{15} \mathrm{~N}\right)$, methionine (methyl- $\mathrm{D}_{3}$ ), S-adenosylmethionione (methyl- $\mathrm{D}_{3}$ ), cystine 3,3'3'3'- $\left.\mathrm{D}_{4}\right)$ and homocystine $\left(3,3,33^{\prime} 4,4,4{ }^{\prime} 4^{\prime}-\mathrm{D}_{8}\right)$ stable isotopes. Standards were diluted to working concentrations of $0.05,0.5,5$, and $50 \mu \mathrm{M}$ in $5 \%$ PCA solution. Derivatization of acidified cell lysates and media was performed as previously described [37]. Briefly, $20 \mu \mathrm{l}$ of internal standard solution was added to acidified cell lysates $(180 \mu \mathrm{l})$. To these samples, $70 \mu \mathrm{l}$ of $\mathrm{KOH} /$ tetrahydroborate buffer was added and centrifuged at $12,000 \times$ g. Supernatants $(200 \mu \mathrm{l})$ were derivatized using the EZ-FAAST Kit per manufacturer's protocol.

\section{HPLC conditions}

HPLC analysis was performed on the Shimadzu LC10AD HPLC system equipped with the SIL-10 AVP auto-sampler, and two LC-AD10 pumps. The chromatographic separation was carried out on a $25 \mathrm{~mm}$ X $2 \mathrm{~mm}$ column supplied by EZ-FAAST (Phenomenex CA). The mobile phase was composed of methanol:water $(80: 20 \mathrm{v} / \mathrm{v})$ containing $1 \mathrm{mM}$ ammonium formate and the total flow rate was set at $0.25 \mathrm{ml} / \mathrm{min} .10 \mu \mathrm{l}$ of each standards plus samples solution was injected with a total run time of $15 \mathrm{~min}$.

\section{Mass spectrometer settings}

Detection of derivatized metabolites and internal standards was carried out with Quattro LC mass spectrometer (Micromass; Waters, MA) in electrospray positive ionization mode. Results were quantified using the MassLynx 3.3 software. Capillary voltage was set to $3 \mathrm{kV}$, source temperature to $130^{\circ} \mathrm{C}$, and nebulizer gas temperature to $400^{\circ} \mathrm{C}$. The nebulizer and analysis cell gas flows (both nitrogen) were set at 80 and $800 \mathrm{~L} / \mathrm{h}$, respectively. The low and high mass resolutions were fixed at 15 for both the first and third quadrupole mass analyzers. The collision gas (argon) pressure in the second quadrupole was set at $1.5 \mathrm{mbar}$. The photomultiplier was fixed at 650. The dwell time and the interchannel delay were fixed at 0.2 and $0.01 \mathrm{~s}$, respectively. The optimized cone voltages and collision energy settings for metabolites detected are listed in Additional file 1: Table S1.

\section{Statistical analysis}

Statistical significance $(\mathrm{p}<0.05)$ was determined using two-way ANOVA followed by a Dunnett's post hoc tests for multiple comparisons between controls and cells treated with different concentrations of LPS and at different time points.

\section{Results}

\section{LPS-dependent changes in the RAW macrophage amino} acid profile

LPS activates macrophage via the classical activation pathway by initiating the Toll-like receptor 4 (TLR-4) and MD2-dependent redox sensitive inflammatory signaling cascade [38]. In LPS-stimulated macrophages, changes in gene expression have been detected as early as $2 \mathrm{hrs}$ after challenge for early-response genes, whereas changes in late-response genes have not been detected until $\sim 24$ hrs after challenge [39].

As shown in Table 1, after 24 hrs incubation of RAW cells in the presence of $1 \mu \mathrm{g} / \mathrm{ml} \mathrm{LPS}$, cellular concentrations of $60 \%(18 / 34)$ of the metabolites measured were significantly altered compared to untreated cultures; concentrations of 11 increased, while 7 decreased. Metabolites that increased (Table 1) were primarily intermediates involved in either Arg or SAA metabolism (Figure 1). The two greatest increases were for Cit and Orn, intermediates produced by NOS and arginase enzymes respectively. Of these two metabolites, Cit exhibited the larger increase, with levels rising from 0.2 $\pm 0.02 \mathrm{nmol} / \mathrm{mg}$ protein in untreated cells to $10.3 \pm 1.8$ $\mathrm{nmol} / \mathrm{mg}$ in LPS-treated cells $(\mathrm{p}<0.0001)$. Orn, an arginase-mediated metabolite of arginine (Figure 1), increased to a lesser extent than Cit, approximately 7fold (Table 1). Put, the rate-limiting substrate for cellular polyamines (Figure 1), also increased to a similar extent, approximately 5 -fold (Table 1 ). To rule out the possibility of artifacts introduced by IAM incubation, intracellular concentrations of Arg, Cit and Orn were extracted with perchloric acid without IAM pretreatment with similar results (Additional file 2: Figure S1). This suggests that IAM did not cause incomplete arginase inactivation during the incubation period and it did not contribute to the LPS-dependent increase in intracellular Orn.

Though their response was modest in comparison to Arg-related intermediates, certain SAA metabolites were also responsive to LPS treatment. Most notably, Cys, the rate-limiting precursor of cellular $\mathrm{GSH}$, increased several-fold in LPS treated cells, from $2.1 \pm 0.7$ to $6.2 \pm 1.7 \mathrm{nmol} / \mathrm{mg}$ protein. Gln is metabolized to form Glu, which serves as a precurser to Arg and GSH. Gln concentration was increased by $\sim 60 \%$ in LPS-treated compared to untreated cells (Table 1). Met and Hcy also increased by $\sim 35$ and $65 \%$, respectively, following LPS 
Table 1 LPS-induced changes in cellular amino acid metabolites

\begin{tabular}{|c|c|c|c|c|c|}
\hline Metabolite & Control $^{a}$ (nmol/mg protein) & LPS $^{b}$ (nmol/mg protein) & $\%$ CHANGE $^{c}$ from Control & Pathway $^{\text {d }}$ & Sig $^{e}$ \\
\hline Cit & $0.2 \pm 0.02$ & $10.3 \pm 1.8$ & 5050.0 & Arg Met & $<0.0001$ \\
\hline Orn & $0.7 \pm 0.3$ & $5.78 \pm 0.8$ & 752.9 & Arg Met & $<0.0001$ \\
\hline Put & $1.2 \pm 0.2$ & $7.5 \pm 2.4$ & 525.0 & Arg Met & $<0.0001$ \\
\hline Cys & $2.1 \pm 0.7$ & $6.2 \pm 1.7$ & 195.2 & SAA Met & $<0.01$ \\
\hline Gln & $6.2 \pm 0.5$ & $16.1 \pm 0.5$ & 159.7 & Arg Met & $<0.01$ \\
\hline Ile+Leu & $1.3 \pm 0.2$ & $3.3 \pm 0.8$ & 153.8 & BCAA & $<0.05$ \\
\hline Phe & $0.6 \pm 0.6$ & $1.0 \pm 0.3$ & 66.7 & EAA & $<0.05$ \\
\hline Hcy & $0.03 \pm 0.01$ & $0.05 \pm 0.02$ & 66.7 & SAA Met & $<0.05$ \\
\hline Ser & $1.6 \pm 0.2$ & $2.2 \pm 0.4$ & 37.5 & SAA Met & $<0.05$ \\
\hline Met & $4.0 \pm 0.4$ & $5.4 \pm 0.3$ & 35.0 & SAA Met & $<0.05$ \\
\hline GSSG & $0.4 \pm 0.1$ & $0.5 \pm 0.1$ & 25.0 & SAA Met & $<0.05$ \\
\hline Asn & $2.3 \pm 0.3$ & $2.6 \pm 0.5$ & 13.0 & & \\
\hline Pro & $5.4 \pm 1.6$ & $6.0 \pm 1.3$ & 11.1 & & \\
\hline Lys & $13.23 \pm 2.85$ & $14.61 \pm 4.34$ & 10.4 & & \\
\hline Ala & $3.3 \pm 0.8$ & $3.6 \pm 0.34$ & 9.1 & & \\
\hline His & $1.5 \pm 0.5$ & $1.6 \pm 0.2$ & 6.7 & & \\
\hline Spd & $13.3 \pm 2.1$ & $13.7 \pm 2.3$ & 3.0 & & \\
\hline Trp & $0.4 \pm 0.1$ & $0.4 \pm 0.1$ & 0.0 & & \\
\hline Tyr & $0.7 \pm 0.3$ & $0.7 \pm 0.24$ & 0.0 & & \\
\hline Val & $0.7 \pm 0.3$ & $0.7 \pm 0.2$ & 0.0 & & \\
\hline SAM & $0.2 \pm 0.04$ & $2.2 \pm 0.2$ & -7.1 & & \\
\hline Thr & $9.2 \pm 2.5$ & $8.3 \pm 1.9$ & -9.8 & & \\
\hline GSH & $46.8 \pm 2.4$ & $37 \pm 4.9$ & -20.9 & SAA Met & $<0.05$ \\
\hline Glu & $37.5 \pm 3.8$ & $24.9 \pm 5.2$ & -33.6 & SAA Met & $<0.05$ \\
\hline Gly & $25.4 \pm 1.0$ & $16.0 \pm 1.1$ & -37.0 & SAA Met & $<0.05$ \\
\hline SAH & $0.2 \pm 0.03$ & $0.1 \pm 0.02$ & -50.0 & SAA Met & $<0.01$ \\
\hline Spm & $23.8 \pm 1.5$ & $8.23 \pm 6.2$ & -65.4 & Arg Met & $<0.01$ \\
\hline Arg & $3.2 \pm 0.13$ & $1.1 \pm 0.11$ & -65.6 & Arg Met & $<0.0001$ \\
\hline Asp & $57.8 \pm 13.8$ & $15.8 \pm 4.0$ & -72.7 & Arg Met & $<0.0001$ \\
\hline
\end{tabular}

RAW macrophage cells $\left(2 \times 10^{6}\right)$ were incubated in the absence (control) or presence of $1 \mu \mathrm{g} / \mathrm{ml}$ LPS (LPS) for 24 hrs. Cellular metabolites were extracted and analyzed as described in Methods. a,b - Metabolites quantified and their corresponding concentrations are listed. Values presented are averages from 5 experiments (mean \pm SD). c- \% change for each of the metabolites in LPS treated cells from control cultures are listed. d- Metabolic pathways for metabolites that were significantly altered by LPS are listed. e- * denotes statistical significance of the differences detected.

Abbreviations: Alanine - Ala; Arginine - Arg; Arginine metabolism - Arg Met; Asparagine - Asn; Aspartate - Asp; Branched Chain Amino Acids - BCAA Citrulline - Cit; Cysteine Cys; Essential Amino Acids - EAA Glutamate - Glu; Glutamine - Gln; Glutathione - GSH; Glutathione disulfide - GSSG; Glycine - Gly; Histidine - His; Homocysteine - Hcy; Isoleucine +Leucine - lle-Leu; Lysine - Lys; Methionine - Met; Ornithine - Orn; Proline - Pro; Putrescine - Put; Phenylalanine - Phe; Sulfur Amino Acid Metabolism - SAA Met; Sadenosylmethionine - SAM; S-adenosylhomocysteine - SAH; Serine - Ser; Spermidine - Spd; Spermine - Spm; Threonine - Thr; Tryptophan - Trp; Tyrosine - Tyr; Valine - Val.

treatment. These metabolites are key components of the transmethylation pathway, which supplies Cys required for GSH synthesis. Lastly, cellular concentrations of GSSG, the homodisulfide of GSH, increased by $25 \%$ in LPS treated cells.

In addition to the 6 metabolites that increased by more than 2-fold following LPS exposure, 7 compounds were significantly decreased. Intracellular Arg and Asp significantly decreased by 65.6 and $72.7 \%$ respectively. Asp is a substrate required for Arg regeneration via the argininosuccinate lyase pathway $[29,40]$. The decreases in both Arg and Asp suggest that LPS imposes an acute depletion of cellular Arg equivalents. Despite a significant increase in cellular Put, cellular levels of polyamines derived from Put decreased. SPM declined from $23.2 \pm$ $1.5 \mathrm{nmol} / \mathrm{mg}$ protein in control cultures to $8.2 \mathrm{nmol} / \mathrm{mg}$ protein in LPS treated cells. Cellular SAH, Gly, Glu and GSH showed more modest declines following LPS treatment. Compared to controls, LPS-treated cells contained $\sim 50 \%$ less cellular SAH, a by-product of SAM methylation reactions. Concentrations of Glu and Gly, constituents of cellular GSH, both declined by $\sim 30 \%$. Cellular 
GSH decreased from $46.6 \pm 2.4$ in untreated cells to 37 $\pm 4.9 \mathrm{nmol} / \mathrm{mg}$ protein in LPS-treated cells. This $20 \%$ loss in cellular GSH, along with similar increases in GSSG concentration, indicate that LPS treatment shifted cellular thiol redox to a more oxidized state.

\section{LPS concentration-dependent effects on Arg metabolism} Evidence suggests that the metabolic fate of Arg is a critical determinant of classical or alternative activation pathways in macrophage cells [9-11]. Effects on the steadystate concentrations of Arg and two major Arg-derived metabolites, Cit and Orn, were measured 24 hrs after treatment with $0,0.1,1,10,100$, and $1,000 \mathrm{ng} / \mathrm{ml} \mathrm{LPS}$ (Figure 2). As shown, significant declines in Arg and increases in Cit were observed when LPS concentrations were at $10 \mathrm{ng} / \mathrm{ml}$ and above. Orn also increased significantly, but only at the two highest LPS concentrations.

The Cit/Orn ratio increased significantly at lower concentrations of LPS $(1 \mathrm{ng} / \mathrm{ml})$ than required to cause a significant increase in either Cit or Orn individually. The maximal increase in the Cit/Orn ratio was observed when cells were treated with $10 \mathrm{ng} / \mathrm{ml}$ LPS. At higher concentrations of LPS (100 and $1000 \mathrm{ng} / \mathrm{ml}$ ), the cellular Cit/Orn ratio decreased to 4.5 and 1.8 from the maximal ratio of 6.6 obtained at $10 \mathrm{ng} / \mathrm{ml}$ LPS. The data indicate that the increase in Orn, which occurred at concentrations of LPS at or above $100 \mathrm{ng} / \mathrm{ml}$, signals a shift in Arg consumption toward urea generation. Orn is a precursor to both proline and the polyamines spermidine and spermine. The concentrations of Pro, and Spd remained unchanged across all concentrations of LPS tested (Table 2). Thus, while Orn increased at higher LPS concentrations, this did not result in increased generation of its products.

\section{Threshold concentrations of LPS}

As shown in Table 1, LPS treatment for 24 hrs strongly increased Arg metabolism. Though less prominent than changes in the Arg pathway, SAA metabolites (notably $\mathrm{GSH}$, which indicates the redox state of the cell) decreased following LPS treatment. These results suggest that Arg and SAA metabolites are highly responsive to LPS-dependent classical M1 activation and may be useful as surrogate markers of inflammation.

The Arg and SAA metabolites that exhibited the greatest change on LPS treatment were Arg, Asp, Orn, and Cit. Arg and Asp exhibited the greatest decrease after LPS treatment, while their products Orn and Cit exhibited the greatest increase. We hypothesized that a ratio of the sums of these metabolites: (Cit + Orn)/(Arg + Asp), which we term the CO/AA ratio, would be highly sensitive to metabolic shifts following LPS treatment. The relative sensitivity of this ratio to LPS was compared to several established amino acid ratios used as

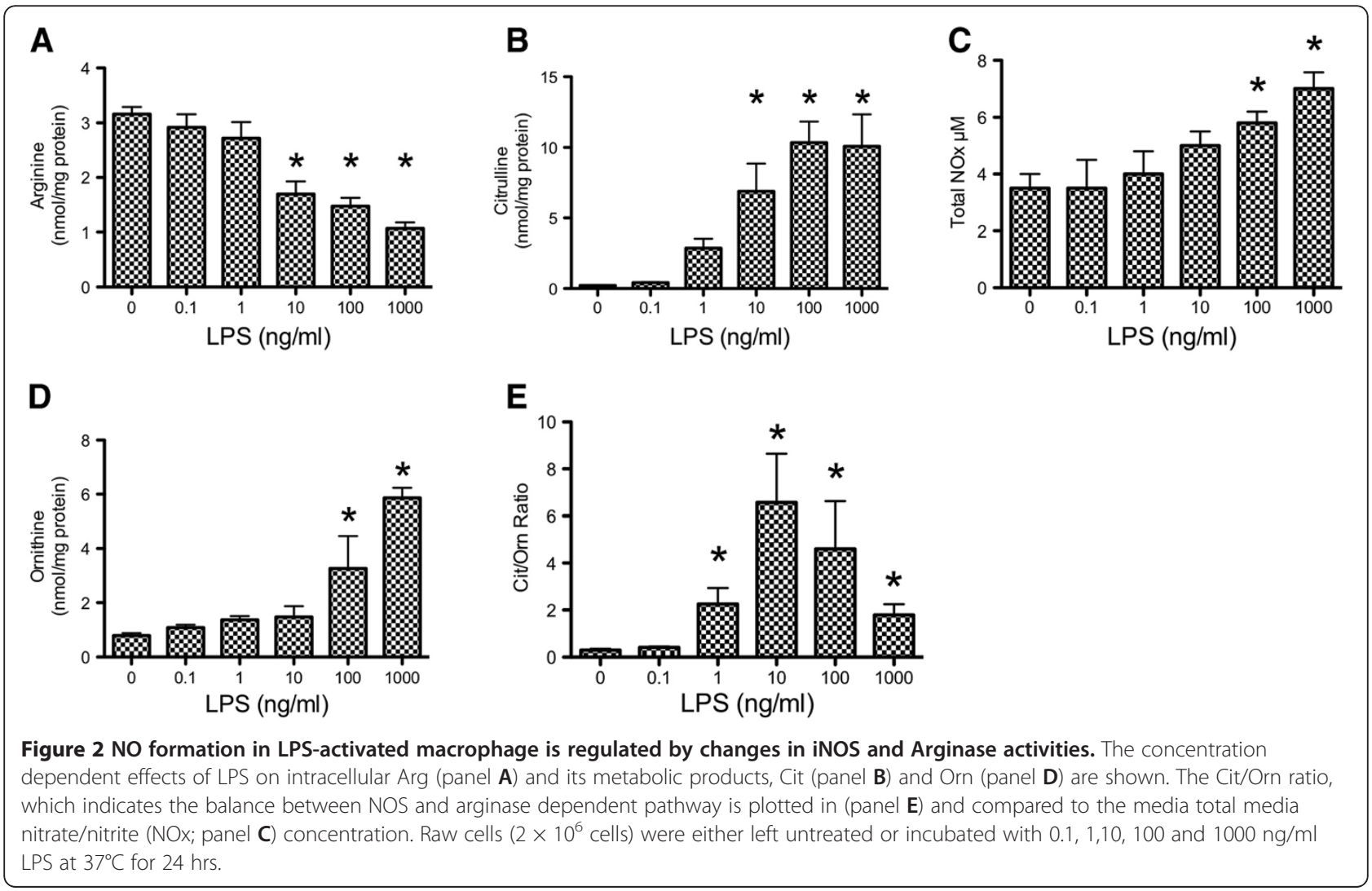


Table 2 LPS-dependent changes in ornithine derived products

\begin{tabular}{ccccccc}
\hline & & \multicolumn{3}{c}{ LPS Concentrations } \\
\cline { 3 - 7 } Metabolite & Control & $\mathbf{0 . 1} \mathbf{~ n g} / \mathbf{m l}$ & $\mathbf{1} \mathbf{~ n g} / \mathbf{m l}$ & $\mathbf{1 0} \mathbf{~ n g} / \mathbf{m l}$ & $\mathbf{1 0 0} \mathbf{~ n g} / \mathbf{m l}$ & $\mathbf{1 0 0 0} \mathbf{~ n g} / \mathbf{m l}$ \\
\hline Orn & $0.78 \pm 0.20$ & $1.07 \pm 0.25$ & $1.36 \pm 0.31$ & $1.47 \pm 0.88$ & $3.26 \pm 0.24^{*}$ & $5.86 \pm 0.83^{* *}$ \\
Put & $1.21 \pm 0.39$ & $2.88 \pm 0.98$ & $6.05 \pm 2.8^{* *}$ & $7.94 \pm 3.11^{* *}$ & $9.56 \pm 4.28^{* *}$ & $9.31 \pm 3.42^{* *}$ \\
Pro & $5.45 \pm 1.62$ & $6.77 \pm 1.36$ & $7.81 \pm 2.90$ & $7.38 \pm 1.98$ & $7.07 \pm 1.82$ & $6.04 \pm 1.33$ \\
Spd & $13.32 \pm 2.09$ & $15.72 \pm 2.28$ & $13.67 \pm 2.35$ & $13.93 \pm 2.09$ & $13.66 \pm 1.60$ & $13.74 \pm 2.38$ \\
Spm & $23.82 \pm 1.55$ & $14.07 \pm 3.05^{*}$ & $12.60 \pm 2.48^{*}$ & $10.69 \pm 2.75^{* *}$ & $7.39 \pm 1.86^{* *}$ & $6.75 \pm 2.04^{* *}$ \\
\hline
\end{tabular}

RAW cells $\left(2 \times 10^{6}\right)$ cells were incubated in the absence (control) or in the presence of $0.1,1,10,100$ and $1000 \mathrm{ng} / \mathrm{ml}$ LPS (LPS) for $24 \mathrm{hrs}$. Cellular metabolites were extracted and analyzed as described in methods. Results are an average of 3 independent experiments. ${ }^{*}$ and ${ }^{* *}$ denotes $p<0.05$ or $p<0.01$, respectively.

biomarkers of LPS- dependent inflammation: SAM/SAH [40], GSH/GSSG [41,42], Spd/Spm [43], and Gln/Glu [44]. In addition to these markers, the media concentration of $\mathrm{NOx}$, was also measured because it is a metabolite-independent measure of RAW cell activication and inflammation [45].

As shown in Figure 3, significant increases in total media NOx following 24 hrs incubation with LPS were detectable only when LPS concentrations were $\geq 100$ $\mathrm{ng} / \mathrm{ml}$. The total media NOx concentration increased from baseline values of $3.5 \pm 0.5 \mu \mathrm{M}$ to $5.8 \pm 0.4$ and 7.0 $\pm 0.6 \mu \mathrm{M}$ in cells treated with 100 and $1000 \mathrm{ng} / \mathrm{ml} \mathrm{LPS}$, respectively. In contrast, $0.1 \mathrm{ng} / \mathrm{ml}$ LPS was sufficient to cause a statistically significant $290 \pm 166 \%$ increase in the CO/AA ratio ( $<<0.01$ ). Further increasing LPS concentrations to 1,10 and 100 and $1000 \mathrm{ng} / \mathrm{ml}$ caused the intracellular CO/AA ratio to rise by $1241 \pm 576,2530 \pm$ $945,4497 \pm 979$, and $6775 \pm 1969 \%$, respectively.
As evident in Figure 3, the CO/AA ratio was most sensitive to metabolic shifts following LPS treatment at all concentrations tested. Significant alterations in other amino acid metabolite markers were only observable after treatment with at least $10 \mathrm{ng} / \mathrm{ml} \mathrm{LPS}$. At $10 \mathrm{ng} / \mathrm{ml}$ LPS the Gln/Glu ratio increased by $280 \pm 69 \%$, whereas the $\mathrm{Spd} / \mathrm{Spm}$ ratio decreased by approximately $50 \%$. As shown, LPS-dependent changes in metabolite ratios linked to cellular sulfur amino acid metabolism, such as SAM/SAH and GSH/GSSG were only observed at LPS concentrations $\geq 100 \mathrm{ng} / \mathrm{ml}$.

\section{Earliest detectable metabolic change following LPS treatment}

To ascertain the earliest time-point following LPS treatment at which metabolic change was detected by the $\mathrm{CO} / \mathrm{AA}$ ratio as compared to the other biomarkers discussed above, RAW cells were either left untreated or

\section{$\square$ Media NOx $\quad$ SAM/SAH \\ (Cit+Orn)/(Arg+Asp) \\ $\mathbb{Q}$ GSH/GSSG \\ Glutamine/Glutamate \\ SPD/SPM}

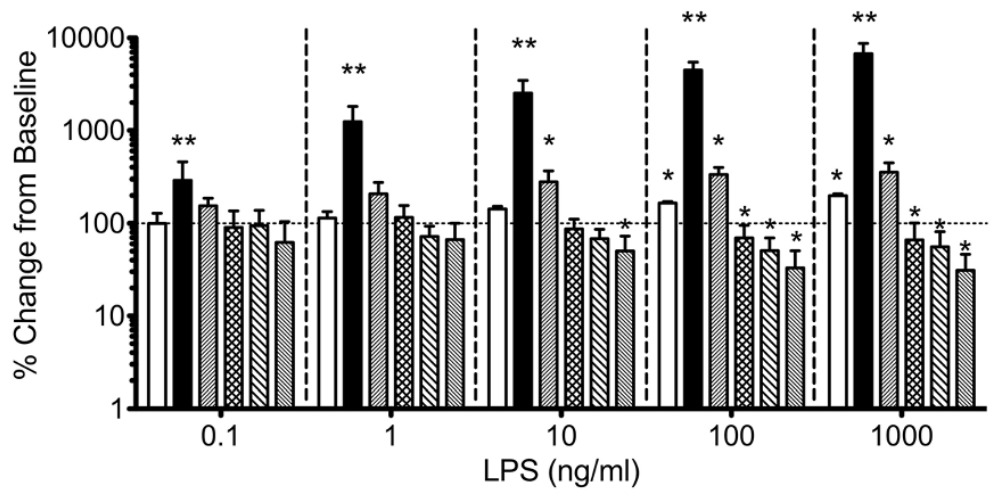

Figure 3 The cellular CO/AA ratio is the most sensitive amino acid-based biomarker of LPS activation. The relative sensitivity of the CO/ AA ratio to varying concentrations of LPS was compared to total media nitrate/nitrite (NOx), Gln/Glu, SAM/SAH, GSH/GSSG, AND Spd/Spm ratios. Raw cells $\left(2 \times 10^{6}\right.$ cells) were either left untreated or incubated with $0.1,1,10,100$ and $1000 \mathrm{ng} / \mathrm{ml}$ LPS at $37^{\circ} \mathrm{C}$ for 24 hrs. Media NOx concentrations and metabolite ratios obtained were normalized to baseline levels in untreated cells and the \% changes from baseline were plotted (mean $\pm \mathrm{SD} ; \mathrm{N}=6$ ). The CO/AA ratio was the sole indicator that was significantly changed, even at $0.1 \mathrm{ng} / \mathrm{ml}$ LPS, and further increased at higher LPS concentrations in a dose-dependent manner. At all concentrations of LPS tested, the changes in CO/AA ratio were greater than other metabolic indices of macrophage activation. * denotes $p<0.05$; ${ }^{* *}$ denotes $p<0.001$. 
treated with $10 \mathrm{ng} / \mathrm{ml}$ LPS for 2, 4, or 6 hrs. As shown in Figure 4A, at this concentration of LPS, the CO/AA ratio significantly increased by $171 \pm 25 \%$ ( $<<0.01$ ) after $4 \mathrm{hrs}$ following LPS treatment, and increased by $294 \pm$ $42 \%$ at 6 hrs. In contrast, total media NOx concentrations and cellular GSH/GSSG ratios remained unchanged relative to controls. Glutamine/glutamate and Spd/Spm ratios significantly increased $4 \mathrm{hrs}$ following LPS challenge (Figure 4B), however the SAM/SAH ratio, which measures the cellular methylation capacity, did not change during the first 6 hrs following LPS addition (Figure 4B).

In summary, the $\mathrm{CO} / \mathrm{AA}$ ratio changed significantly at lower LPS concentrations and at earlier times following challenge than the other metabolic indices of macrophage activation to which it was compared.

\section{Discussion}

In the present work, a comprehensive Arg/thiol redox amino acid metabolomics assay was used to monitor amino acid metabolic changes following LPS challenge of RAW macrophage cells. The Arg-Cit-NO cycle and arginase pathways were identified as most sensitive to LPS. This assay was also useful in determining the temporal relastionships between these pathways and cellular redox regulation.

As shown in Table 1 and Figures 3-4, Arg, Asp, Cit and Orn were most significantly affected by LPS treatment. Since these metabolites are involved in Arg catabolism and synthesis, these results indicate that Arg metabolic pathways are most immediately impacted by LPS. The concentration ratio $(\mathrm{Cit}+\mathrm{Orn}) /(\mathrm{Arg}+\mathrm{Asp})$ was most sensitive to LPS challenge, changing significantly at lower concentrations and earlier times following LPS treatment compared to total media NOx and other commonly used metabolic biomarkers of cellular methylation, redox, polyamine and nitrogen balance status (Figure 3).
Because the CO/AA ratio significantly changed prior to cellular GSH/GSSG redox change, it appears to be a redox independent biomarker of macrophage activation. Thus, simultaneous quantification of CO/AA and thiol redox ratios allows for concurrent analysis of metabolic shifts during cellular inflammation and oxidative stress.

\section{Arginase and iNOS regulation}

Results presented here reveal the importance of arginase in iNOS regulation. LPS is known to acutely stimulate iNOS within the first 24 hrs of macrophage activation $[11,46]$ and the induction of iNOS and subsequent NO generation are critical to macrophage innate immune functions [47]. In contrast, the role of arginase in iNOS regulation during the initial phases of macrophage activation is less well understood. The ratio of Cit/Orn increased linearly with LPS concentration, with maximal effects observed at $10 \mathrm{ng} / \mathrm{L}$, declining at 100 and 1000 $\mathrm{ng} / \mathrm{ml}$, due to the rise in Orn (Figure 2). These data suggest that the relatively low sensitivity of arginase enzymes to LPS at low concentrations allows for maximal rates of iNOS activity, but at higher LPS concentrations, induction of arginase resulting in increased Orn, may prevent the toxicity of excess NO generation. Arginase inhibition therapy has been proposed to improve endothelial function by increasing Arg available for $\mathrm{NO}$ generation [48,49]. Results reported here suggest that arginase activity differs depending on LPS burden, and that arginase inhibition when LPS is high may exacerbate inflammation by excessive $\mathrm{NO}$ production.

\section{Type I and Type II arginase isoforms}

Results presented here suggest that Arg-derived metabolites may be useful in determining the type of arginase isoform expressed in cells [11]. Macrophage express both type I and type II arginases. The type I (cytoplasmic) isoform is typically associated with the TH2 alternative macrophage activation pathway, which is
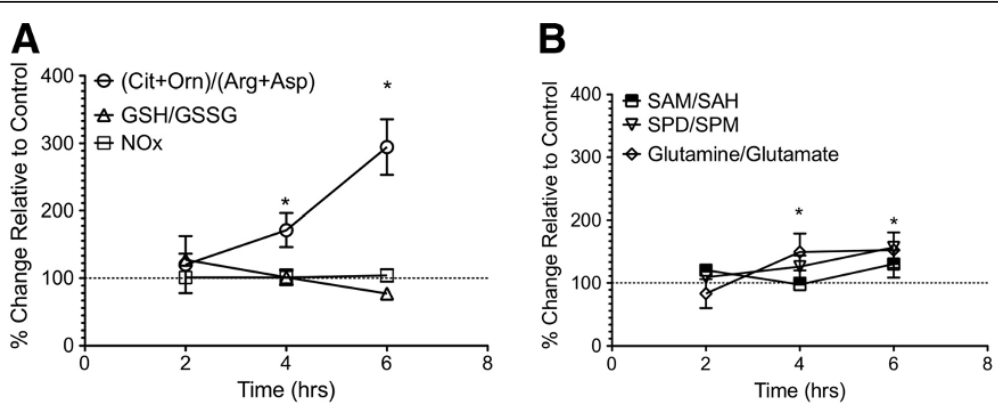

Figure 4 Shifts in the macrophage CO/AA ratio temporally precede changes in other amino acid metabolites and total media NOx levels. Temporal changes in the CO/AA ratio were plotted against other metabolic indices of macrophage activation. Briefly, RAW cells $\left(2 \times 10^{6}\right.$ cells) were either left untreated or treated with $10 \mathrm{ng} / \mathrm{ml}$ LPS for 2, 4 or 6 hrs. At each time point, cells were harvested and metabolites (mean \pm SD; $N=6$ ) were quantified as described in Methods. Panel A shows time-dependent changes in the ratios of CO/AA and GSH/GSSG, and total media nitrate/nitrite concentrations (NOx). * denotes statistical significance $(P<0.05)$. 
characterized by elevated polyamine and proline production $[9,49,50]$. In contrast, the type II (mitochondrial) form of arginase is induced only by TH1 classical activation, and is charcterized by the lack of polyamine and proline production. LPS induces TH1 classical activation and thus only type II arginase is induced [11]. Results presented here are consistent with TH1 activation since this increase was not accompanied by an increase in spermidine, spermine, or proline (Table 2), though Orn was increased at very high LPS concentrations ( $>100$ $\mathrm{ng} / \mathrm{ml})$. Thus, increased Orn/polyamine or proline ratios may be indicative of arginase II induction whereas the opposite may indicate arginase I induction. This suggestion is plausible because the downstream enzymes for polyamine and proline synthesis are cytosolic enzymes and Orn synthesized in mitochondria may not feed into these pathways.

\section{A role for Asp in Arg synthesis in macrophage?}

LPS-stimulated macrophage metabolize Arg at a greatly enhanced rate, and therefore a continous supply of Arg is needed by these cells to support their immune functions. To meet this demand, LPS-activated macrophage cells increase both the uptake and synthesis of Arg [29,51,52]. In response to LPS $(1 \mu \mathrm{g} / \mathrm{ml})$ treatment (Table 1 and Figure 2), the concentrations of Cit and Orn, the two metabolic products of Arg, increased significantly and greatly exceeded the amount of Arg loss from levels found in untreated cells. As this was a steady-state measurement, the extent of Arg loss in LPS activated cells may underestimate the actual rate of Arg uptake and resynthesis.

The cellular uptake of Arg is mediated by the cationic amino acid transporter 2 (CAT2) [53]. CAT2 is coinduced with iNOS in LPS-treated macrophages [53]. Inhibition of CAT2 decreases iNOS-dependent Cit/NO generation without impacting the level of iNOS protein abundance [53]. Although Arg is its preferred substrate, CAT2 is also capable of transporting other cationic amino acids, such as Orn and Lys, that can potentially compete with Arg import and reduce Cit/NO output. However, this is unlikey to be the case in this model because the concentration of Lys or Orn in the media was far below the concentration required for competitive inhibition of Arg uptake and subsequent $\mathrm{NO}$ and/or Cit synthesis [51,53].

Cit (produced along with NO from Arg) can synthesize Arg by the combined actions of the argininosuccinate synthetase (ASS) and argininosuccinate lyase (ASL) [28]. ASS and ASL are known to increase in RAW macrophage following LPS challenge [28,29,54]. Though Asp is required for Cit-dependent Arg synthesis by the ASS/ASL pathway, a role for Asp in Arg synthesis in macrophage has not been established. Although this report does not conclusively establish the metabolic fate of Asp on LPS challenge, the large decrease in both Asp and Arg (Table 1) suggest potential involvement of Asp in Arg synthesis. The contribution of Asp to support Arg-Cit-NO cycle may be particularly more important in RAW macrophages because these cells may not contain active carbamyl phosphate synthetase (CPS) or ornithine transcarbamylase enzymes (OTC) required for converting other amino acids, such as Pro, to synthesize Cit and Arg [29].

It should be noted that unlike plasma or other widely used media such as RPMI, the DMEM media used in this study lacks Ala, Pro, Glu, Asp and Asn. It is possible that this deficiency would have prevented the utilization of these amino acids to regenerate Arg, that would otherwise occur under amino acid replete conditions. However, cellular biosynthesis of these nonessential amino acids would also be expected, which would be expected to mitigate any deficiency. While deficiency could theoretical impact the rate of Arg replenishment, this is unlikely to alter our major findings because availability of these substrates do not directly modulate LPS-dependent up-regulation of iNOS and arginase expression.

\section{Oxidation of cellular GSH following LPS challenge occurs secondary to iNOS activation}

Oxidative stress modulates the LPS-dependent activation of pro-inflammatory genes, including the iNOS protein [55-57]. Nuclear Factor-kappa-light-chain-enhancer of activated B cells (NFkB) is a key inflammatory transcription factor responsible for up-regulating inflammatory genes following LPS exposure [56]. LPS increases macrophage oxidant generation from multiple sources such as mitochondria [58] and the NADPH oxidase enzyme [59]. ROS mediated oxidation of critical thiol in MAP kinase phosphatase-1, a key phosphatase enzyme in macrophage cells, has been shown to be involved in the activation of upstream MAP kinase proteins (p38, JNK, and Erk1/2) responsible for NFkB activation [46]. Because of the potential role of oxidative stress in iNOS activation, the oxidation of the GSH pool may precede LPS-dependent NFkB activation. However, the analysis here (Figure 4A) indicates that oxidation of cellular GSH, following LPS challenge, occurs secondary to increased Arg-Cit-NO pathway activity, as no significant declines in GSH/GSSG ratios are observed during the first 6 hrs following LPS addition. This result suggests that the initial activation of iNOS does not require a GSH redox pool oxidation. However, it is possible that subsequent oxidation of the GSH pool may play a role in propagation rather than the initiation of the LPS inflammation signaling. 


\section{A new mechanism contributing to inflammatory signaling?}

In addition to GSH, LPS addition caused the elevation in cellular Cys and Hcy. Cys and Hcy exert pro-oxidant effects in cells by oxidizing protein thiols through Scysteinylation or S-homocysteinylation [12,16,60,61]. However, there is no evidence that Cys and Hcy have any involvement in inflammatory signaling. The rise in Cys and Hcy observed after LPS challenge (Table 1), can cause oxidation of protein disulfides by means of mixed disulfide formation. The potential role of Cys or Hcy-dependent Sthiolation in macrophage redox signaling is currently unknown. Given the reactivity of Cys and Hcy to protein Sthiolation, the LPS-dependent increase in their levels, as seen in this study, indicates that they may represent nonoxidant mediated redox signaling mechanism.

\section{Clinical implications}

LPS has been implicated not only in sepsis but also as a potential trigger of subclinical inflammation in obesity and in cardiovascular diseases $[62,63]$. A possible mechanism for inflammation in these diseases may involve activation of macrophage cells by low threshold grade LPS (1 $\mathrm{ng} / \mathrm{ml}$ ), which cooperatively enhances the proatherogenic effects of oxidized LDL [63]. Detection of cellular effects of such low levels of LPS is challenging and the metabolomics data presented indicate that the $\mathrm{OC} / \mathrm{AA}$ ratio is significantly increased in response to low concentration of LPS $(0.1 \mathrm{ng} / \mathrm{ml})$ than existing biomarkers (Figure 3). When combined with its ability to monitor major physiological small molecule thiol redox states, this assay may be useful in quantifying the onset of sub-clinical inflammation mediated by monocytes/ macrophage cells.

Prospective human studies have shown that plasma ratios of Arg/Cit + Orn is associated with increased risk for developing adverse cardiovascular disease outcomes in healthy adults and risk of morbidity and mortality in sickle cell patients $[64,65]$. Plasma thiol redox perturbations occur in the course of aging and development of agerelated diseases $[12,16]$. Inflammation in healthy individuals with or without oxidative stress may have different clinical consequences. The ability to measure both processes, as in this present study, may be clinically useful in further clarifying the role of inflammation in disease. During its development phase, this assay was succesfully applied to monitor leukocyte oxidative stress in children with austism spectrum disease [66], erythrocyte oxidative stress in sickle cell patients [67], plasma and erythryocyte oxidative stress in thalassemia patients [37], oxidative stress in lung fibroblasts caused by cystic fibrosis conductance transporter mutation [68] and cigarette exposure [69]. Inflammation in healthy individuals with or without oxidative stress may have different clinical consequences.
The ability to quantify shifts in both inflammation and redox pathways, as presented in this paper, may be clinically useful in further clarifying the role of inflammation in diseases.

\section{Conclusions}

Amino acid metabolism changes with activation states of macrophage. However, few studies have explored the potential of amino acid metabolites as sensitive biomarkers for inflammation and redox stress. By comprehensively quantifying Arg and SAAs and their metabolic intermediates, the early metabolic shifts during macrophage activation were established, and the $\mathrm{CO} / \mathrm{AA}$ ratio was identified as a new sensitive biomarker of macrophage inflammation. Additionally, mechanistic insights into how specific changes in Arg-Cit-NO Cycle relate to cellular redox and polyamine balance were also suggested. Specifically, data suggest that GSH redox loss is not required for iNOS activation. The concentrationdependent effects of LPS on Cit/Orn balance and polyamines suggests that activation of mitochondrial type II arginase is required for preventing excessive iNOS activity, but does not result in increased cellular polyamine content. It is suggested that monitoring macrophage health in human plasma may permit early identification of sub-clinical inflammation and oxidative stress.

\section{Additional files}

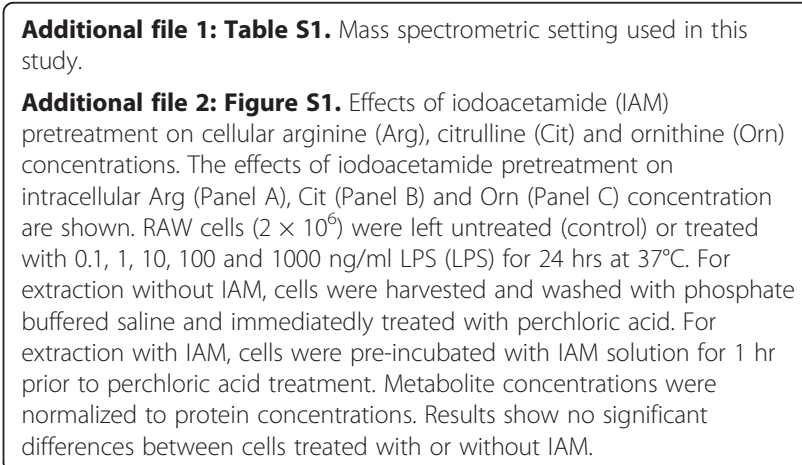

\section{Abbreviations}

Ala: Alanine; Arg: Arginine; Asn: Asparagine; Asp: Aspartate; ASL: Argninosuccinate Lyase; ASS: Argininosuccinate Synthetase; BHMT: Betaine Hydroxymethyl Transferase; Cit: Citrulline; Cys: Cysteine; CBS: Cystathionine Beta-synthase; CL: Cystathionine gamma-Lyase; CPS: carbamyl phosphate synthetase; GGT: Gamma-Glutamyl Transpeptidase; GCL: Gamma-Glutamylcysteine Ligase; GSH: Glutathione; GSSG: Glutathione disulfide; GS: Glutathione synthase; Glu: Glutamate; Gln: Glutamine; Gln Syn: Glutamine Synthase; Gly: Glycine; His: Histidine; Hcy: Homocysteine; IAM: Iodoacetamide; Ile-Leu: Isoleucine +Leucine;

IPCF: Isopropylchloroformate; LPS: Lipopolysaccharides; Met: Methionine; MAT: Methionine Adenosyl Transferase; MT: Methyl Transferase; MS: Methionine Synthase; NOS: Nitric Oxide Synthase; Orn: Ornithine; ODC: Ornithine Decarboxylase; OTC: Ornithine transcarbamylase; Pro: Proline; Put: Putrescine; PAO: Polyamine Oxidase; SAM: S-adenosylmethionine; SAMDC: S-Adenosylmehtionine Decarboxylase; SAH: S-

adenosylhomocysteine; SAHH: S-adenosylhomocysteine hydrolyase; 
Ser: Serine; SPD: Spermidine; Spd Syn: Spermidine Synthase; Spm Syn: Spermine synthase; Spm: Spermine; SSAT: Spermidine/Spermine N1 acetyltransferase, Thr, Threonine; Trp: Tryptophan; Tyr: Tyrosine; Val: Valine.

\section{Competing interests}

No conflicting interests.

\section{Authors' contributions}

Kim, R and Lee, D performed the experiments. Suh, JH designed the study, performed mass spectrometry analysis, interpreted data, and wrote the manuscript. All authors read and approved the final manuscript.

\section{Acknowledgements}

J. Suh would like to thank Drs. Hagen, TM, Ames, BN and McCann J for helpful discussion and critical review of the manuscript. Support for this research was provided by the Ames Foundation, the Stephen Bechtel Fund within S.D. Bechtel, Jr. Foundation, the Addi Cassi Fund within the Ara Parseghian Medical Research Foundation and the Hadley Hope Fund.

Received: 12 January 2012 Accepted: 23 September 2012 Published: 4 October 2012

\section{References}

1. Libby P: Inflammatory mechanisms: The molecular basis of inflammation and disease. Nutr Rev 2007, 65:S140-S146

2. Chiurchiù V, Maccarrone M: Chronic inflammatory disorders and their redox control: From molecular mechanisms to therapeutic opportunities. Antioxid Redox Signal 2011, 15:2605-2641.

3. Balagopal PB, de Ferranti SD, Cook S, Daniels SR, Gidding SS, Hayman LL, McCrindle BW, Mietus-Snyder ML, Steinberger J, Council on Epidemiology and Prevention: Nontraditional risk factors and biomarkers for cardiovascular disease: Mechanistic, research, and clinical considerations for youth: A scientific statement from the american heart association. Circulation 2011, 123:2749-2769.

4. Barocas DA, Motley S, Cookson MS, Chang SS, Penson DF, Dai Q, Milne G, Roberts LJ, Morrow J, Concepcion RS, Smith JA, Fowke JH: Oxidative stress measured by urine $F_{2}$-isoprostane level is associated with prostate cancer. J Urol 2011, 185:2102-2107.

5. Karakas M, Koenig W, Zierer A, Herder C, Rottbauer W, Baumert J, Meisinger C, Thorand B: Myeloperoxidase is associated with incident coronary heart disease independently of traditional risk factors: Results from the MONICA/KORA augsburg study. J Intern Med 2012, 271:43-50.

6. van der Zwan $L P$, Scheffer PG, Dekker JM, Stehouwer CD, Heine RJ, Teerlink T: Systemic inflammation is linked to low arginine and high ADMA plasma levels resulting in an unfavourable NOS substrate-to-inhibitor ratio: The hoorn study. Clin Sci (Lond) 2011, 121:71-78,

7. Van Guilder GP, Hoetzer GL, Greiner JJ, Stauffer BL, Desouza CA: Influence of metabolic syndrome on biomarkers of oxidative stress and inflammation in obese adults. Obesity (Silver Spring) 2006, 14:2127-2131.

8. Hamirani YS, Pandey S, Rivera JJ, Ndumele C, Budoff MJ, Blumenthal RS, Nasir K: Markers of inflammation and coronary artery calcification: A systematic review. Atherosclerosis 2008, 201:1-7.

9. Albina JE, Caldwell MD, Henry WL, Mills CD: Regulation of macrophage functions by l-arginine. J Exp Med 1989, 169:1021-1029.

10. Albina JE, Mills CD, Henry WL, Caldwell MD: Temporal expression of different pathways of 1-arginine metabolism in healing wounds. J Immunol 1990, 144:3877-3880.

11. Morris SM, Kepka-Lenhart D, Chen LC: Differential regulation of arginases and inducible nitric oxide synthase in murine macrophage cells. Am J Physiol 1998, 275:E740-E747.

12. Go YM, Jones DP: Cysteine/cystine redox signaling in cardiovascular disease. Free Radic Biol Med 2011, 50:495-509.

13. Brosnan JT, Brosnan ME: The sulfur-containing amino acids: An overview. J Nutr 2006, 136:1636S-1640S.

14. Finkelstein JD: Inborn errors of sulfur-containing amino acid metabolism. J Nutr 2006, 136:1750S-1754S.

15. Schafer FQ, Buettner GR: Redox environment of the cell as viewed through the redox state of the glutathione disulfide/glutathione couple. Free Radic Biol Med 2001, 30:1191-1212.

16. Jones DP: Redefining oxidative stress. Antioxid Redox Signal 2006, 8:1865-1879.
17. Wang G, Siow $Y L$, Karmin O: Homocysteine induces monocyte chemoattractant protein-1 expression by activating NFkB in THP-1 macrophages. Am J Physiol Heart Circ Physiol 2001, 280:H2840-H2847.

18. Poddar R, Sivasubramanian N, DiBello PM, Robinson K, Jacobsen DW: Homocysteine induces expression and secretion of monocyte chemoattractant protein-1 and interleukin-8 in human aortic endothelial cells: Implications for vascular disease. Circulation 2001, 103:2717-2723.

19. Moat SJ, Bonham JR, Powers HJ: Role of aminothiols as a component of the plasma antioxidant system and relevance to homocysteinemediated vascular disease. Clin Sci (Lond) 2001, 100:73-79.

20. Hofmann MA, Lalla E, Lu Y, Gleason MR, Wolf BM, Tanji N, Ferran L, Kohl B, Rao V, Kisiel W, Stern DM, Schmidt AM: Hyperhomocysteinemia enhances vascular inflammation and accelerates atherosclerosis in a murine model. J Clin Invest 2001, 107:675-683.

21. Ozkan Y, Ozkan E, Simşek B: Plasma total homocysteine and cysteine levels as cardiovascular risk factors in coronary heart disease. Int I Cardiol 2002, 82:269-277.

22. Weiss N, Keller C, Hoffmann U, Loscalzo J: Endothelial dysfunction and atherothrombosis in mild hyperhomocysteinemia. Vasc Med 2002 7:227-239.

23. Dhawan SS, Eshtehardi P, McDaniel MC, Fike LV, Jones DP, Quyyumi AA, Samady $\mathrm{H}$ : The role of plasma aminothiols in the prediction of coronary microvascular dysfunction and plaque vulnerability. Atherosclerosis 2011, 219:266-272.

24. Zhang H, Forman HJ, Choi J: Gamma-glutamyl transpeptidase in glutathione biosynthesis. Methods Enzymol 2005, 401:468-483.

25. Lee DH, Jacobs DR: Association between serum gammaglutamyltransferase and c-reactive protein. Atherosclerosis 2005, 178:327-330.

26. Bo S, Gambino R, Durazzo M, Guidi S, Tiozzo E, Ghione F, Gentile L, Cassader $M$, Pagano GF: Associations between gamma-glutamyl transferase, metabolic abnormalities and inflammation in healthy subjects from a population-based cohort: A possible implication for oxidative stress. World I Gastroenterol 2005, 11:7109-7117.

27. Giral P, Jacob N, Dourmap C, Hansel B, Carrié A, Bruckert E, Girerd X, Chapman MJ: Elevated gamma-glutamyltransferase activity and perturbed thiol profile are associated with features of metabolic syndrome. Arterioscler Thromb Vasc Biol 2008, 28:587-593.

28. Jackson MJ, Allen SJ, Beaudet AL, O'Brien WE: Metabolite regulation of argininosuccinate synthetase in cultured human cells. J Biol Chem 1988, 263:16388-16394.

29. Nussler AK, Billiar TR, Liu ZZ, Morris SM: Coinduction of nitric oxide synthase and argininosuccinate synthetase in a murine macrophage cell line. Implications for regulation of nitric oxide production. J Biol Chem 1994, 269:1257-1261.

30. Guan X, Hoffman B, Dwivedi C, Matthees DP: A simultaneous liquid chromatography/mass spectrometric assay of glutathione, cysteine, homocysteine and their disulfides in biological samples. $J$ Pharm Biomed Anal 2003, 31:251-261.

31. Camera E, Rinaldi M, Briganti S, Picardo M, Fanali S: Simultaneous determination of reduced and oxidized glutathione in peripheral blood mononuclear cells by liquid chromatography-electrospray mass spectrometry. J Chromatogr B: Biomed Sci Appl 2001, 757:69-78.

32. Giustarini D, Dalle-Donne I, Colombo R, Milzani A, Rossi R: An improved HPLC measurement for GSH and GSSG in human blood. Free Radic Biol Med 2003, 35:1365-1372

33. Zhu P, Oe T, Blair IA: Determination of cellular redox status by stable isotope dilution liquid chromatography/mass spectrometry analysis of glutathione and glutathione disulfide. Rapid Commun Mass Spectrom 2008, 22:432-440.

34. Harwood DT, Kettle AJ, Brennan S, Winterbourn CC: Simultaneous determination of reduced glutathione, glutathione disulphide and glutathione sulphonamide in cells and physiological fluids by isotope dilution liquid chromatography-tandem mass spectrometry. Chromatogr B Analyt Technol Biomed Life Sci 2009, 877:3393-3399.

35. Brown CM, Becker JO, Wise PM, Hoofnagle AN: Simultaneous determination of 6 l-arginine metabolites in human and mouse plasma by using hydrophilic-interaction chromatography and electrospray tandem mass spectrometry. Clin Chem 2011, 57:701-709.

36. Husek P: Chloroformates in gas chromatography as general purpose derivatizing agents. J Chromatogr B: Biomed Sci Appl 1998, 717:57-91. 
37. Suh JH, Kim R, Yavuz B, Lee D, Lal A, Ames BN, Shigenaga MK: Clinical assay of four thiol amino acid redox couples by LC-MS/MS: Utility in thalassemia. J Chromatogr B Analyt Technol Biomed Life Sci 2009, 877:3418-3427.

38. Raetz CR, Whitfield C: Lipopolysaccharide endotoxins. Annu Rev Biochem 2002, 71:635-700.

39. Aung HT, Schroder $K$, Himes SR, Brion K, van Zuylen W, Trieu A, Suzuki H, Hayashizaki Y, Hume DA, Sweet MJ, Ravasi T: LPS regulates proinflammatory gene expression in macrophages by altering histone deacetylase expression. FASEB J 2006, 20:1315-1327.

40. Garg S, Vitvitsky V, Gendelman HE, Banerjee R: Monocyte differentiation, activation, and mycobacterial killing are linked to transsulfurationdependent redox metabolism. J Biol Chem 2006, 281:38712-38720.

41. Ferret PJ, Soum E, Negre O, Fradelizi D: Auto-protective redox buffering systems in stimulated macrophages. BMC Immunol 2002, 3:3.

42. Srisook K, Cha YN: Super-induction of HO-1 in macrophages stimulated with lipopolysaccharide by prior depletion of glutathione decreases iNOS expression and NO production. Nitric Oxide 2005, 12:70-79.

43. Babbar N, Murray-Stewart T, Casero RA: Inflammation and polyamine catabolism: The good, the bad and the ugly. Biochem Soc Trans 2007, 35:300-304.

44. Newsholme P: Why is I-glutamine metabolism important to cells of the immune system in health, postinjury, surgery or infection? J Nutr 2001, 131:2515S-2522S. discussion 2523S-4S.

45. Tsikas D: Methods of quantitative analysis of the nitric oxide metabolites nitrite and nitrate in human biological fluids. Free Radic Res 2005 , 39:797-815.

46. Nelin LD, Wang X, Zhao Q, Chicoine LG, Young TL, Hatch DM, English BK, Liu Y: MKP-1 switches arginine metabolism from nitric oxide synthase to arginase following endotoxin challenge. Am J Physiol Cell Physiol 2007, 293:C632-C640.

47. MacMicking J, Xie Q, Nathan C: Nitric oxide and macrophage function. Annu Rev Immunol 1997, 15:323-350.

48. Berkowitz DE, White R, Li D, Minhas KM, Cernetich A, Kim S, Burke S, Shoukas AA, Nyhan D, Champion HC, Hare JM: Arginase reciprocally regulates nitric oxide synthase activity and contributes to endothelial dysfunction in aging blood vessels. Circulation 2003, 108:2000-2006.

49. Morris SM: Recent advances in arginine metabolism: Roles and regulation of the arginases. Br J Pharmacol 2009, 157:922-930.

50. Mills CD, Kincaid K, Alt JM, Heilman MJ, Hill AM: M-1/M-2 macrophages and the Th1/Th2 paradigm. J Immunol 2000, 164:6166-6173.

51. Bogle RG, Baydoun AR, Pearson JD, Moncada S, Mann GE: L-arginine transport is increased in macrophages generating nitric oxide. Biochem $J$ 1992, 284(Pt 1):15-18.

52. Morris SM Jr, Billiar TR: New insights into the regulation of inducible nitric oxide synthesis. American Journal of Physiology-Endocrinology And Metabolism 1994, 266:E829-E839.

53. Nicholson B, Manner CK, Kleeman J, MacLeod CL: Sustained nitric oxide production in macrophages requires the arginine transporter CAT2. J Biol Chem 2001, 276:15881-15885.

54. Salimuddin, Nagasaki A, Gotoh T, Isobe H, Mori M: Regulation of the genes for arginase isoforms and related enzymes in mouse macrophages by lipopolysaccharide. Am J Physiol 1999, 277:E110-E117.

55. Rahman I: Regulation of nuclear factor-kappa B, activator protein-1, and glutathione levels by tumor necrosis factor-alpha and dexamethasone in alveolar epithelial cells. Biochem Pharmacol 2000, 60:1041-1049.

56. Haddad JJ: Redox regulation of pro-inflammatory cytokines and ikappa B-alpha/NF-kappa B nuclear translocation and activation. Biochem Biophys Res Commun 2002, 296:847-856.

57. Nicolls MR, Haskins K, Flores SC: Oxidant stress, immune dysregulation, and vascular function in type I diabetes. Antioxid Redox Signal 2007, 9:879-889.

58. Maitra U, Singh N, Gan L, Ringwood L, Li L: IRAK-1 contributes to lipopolysaccharide-induced reactive oxygen species generation in macrophages by inducing NOX-1 transcription and rac1 activation and suppressing the expression of antioxidative enzymes. J Biol Chem 2009, 284:35403-35411.

59. Matthiesen $S$, Lindemann D, Warnken $M$, Juergens UR, Racké K: Inhibition of NADPH oxidase by apocynin inhibits lipopolysaccharide (LPS) induced up-regulation of arginase in rat alveolar macrophages. Eur J Pharmacol 2008, 579:403-410.
60. Barbato JC, Catanescu O, Murray K, DiBello PM, Jacobsen DW: Targeting of metallothionein by l-homocysteine: A novel mechanism for disruption of zinc and redox homeostasis. Arterioscler Thromb Vasc Biol 2007, 27:49-54.

61. Rossi R, Giustarini D, Milzani A, Dalle-Donne I: Cysteinylation and homocysteinylation of plasma protein thiols during ageing of healthy humans. J Cell Mol Med 2009, 13:3131-3140.

62. Lajunen T, Vikatmaa P, Bloigu A, Ikonen T, Lepäntalo M, Pussinen PJ, Saikku $P$, Leinonen M: Chlamydial LPS and high-sensitivity CRP levels in serum are associated with an elevated body mass index in patients with cardiovascular disease. Innate Immun 2008, 14:375-382.

63. Wiesner P, Choi SH, Almazan F, Benner C, Huang W, Diehl CJ, Gonen A, Butler S, Witztum JL, Glass CK, Miller YI: Low doses of lipopolysaccharide and minimally oxidized low-density lipoprotein cooperatively activate macrophages via nuclear factor kappa B and activator protein-1: Possible mechanism for acceleration of atherosclerosis by subclinical endotoxemia. Circ Res 2010, 107:56-65.

64. Tang WH, Wang Z, Cho L, Brennan DM, Hazen SL: Diminished global arginine bioavailability and increased arginine catabolism as metabolic profile of increased cardiovascular risk. J Am Coll Cardiol 2009, 53:2061-2067.

65. Morris CR, Kato GJ, Poljakovic M, Wang X, Blackwelder WC, Sachdev V, Hazen SL, Vichinsky EP, Morris SM, Gladwin MT: Dysregulated arginine metabolism, hemolysis-associated pulmonary hypertension, and mortality in sickle cell disease. JAMA 2005, 294:81-90.

66. Suh JH, Walsh WJ, McGinnis WR, Lewis A, Ames BN: Altered sulfur amino acid metabolism in immune cells of children diagnosed with autism. Am J Biochem Biotechnol 2008, 4:105-113.

67. Morris CR, Suh JH, Hagar W, Larkin S, Bland DA, Steinberg MH, Vichinsky EP, Shigenaga M, Ames B, Kuypers FA, Klings ES: Erythrocyte glutamine depletion, altered redox environment, and pulmonary hypertension in sickle cell disease. Blood 2008, 111:402-410.

68. Schwarzer C, Illek B, Suh JH, Remington SJ, Fischer H, Machen TE: Organelle redox of CF and CFTR-corrected airway epithelia. Free Radic Biol Med 2007, 43:300-316.

69. Serikov VB, Leutenegger C, Krutilina R, Kropotov A, Pleskach N, Suh JH, Tomilin NV: Cigarette smoke extract inhibits expression of peroxiredoxin $\mathrm{V}$ and increases airway epithelial permeability. Inhal Toxicol 2006, 18:79-92.

doi:10.1186/1476-9255-9-37

Cite this article as: Suh et al:: A new metabolomic assay to examine inflammation and redox pathways following LPS challenge. Journal of Inflammation 2012 9:37.

\section{Submit your next manuscript to BioMed Central and take full advantage of:}

- Convenient online submission

- Thorough peer review

- No space constraints or color figure charges

- Immediate publication on acceptance

- Inclusion in PubMed, CAS, Scopus and Google Scholar

- Research which is freely available for redistribution
C) Biomed Central 